\title{
How to Overcome the Dichotomous Nature of Smart City Research: Proposed Methodology and Results of a Pilot Study
}

\author{
Luca Mora $^{a *}$, Mark Deakin ${ }^{\mathrm{b}}$, Alasdair Reid ${ }^{\mathrm{c}}$ and Margarita Angelidou ${ }^{\mathrm{d}}$ \\ a Edinburgh Napier University, The Business School, Edinburgh, UK, L.Mora@napier.ac.uk \\ b Edinburgh Napier University, School of Engineering and Built Environment, Edinburgh, UK, M.Dea- \\ kin@napier.ac.uk \\ c Edinburgh Napier University, School of Engineering and Built Environment, Edinburgh, UK, \\ Al.Reid@napier.ac.uk \\ d Aristotle University of Thessaloniki, Faculty of Engineering, Thessaloniki, GR, mangel@auth.gr
}

${ }^{*}$ Corresponding author

\begin{abstract}
Overcoming the dichotomous nature of smart city research is fundamental to provide cities with a clear understanding of how smart city development should be approached. This paper introduces a research methodology for conducting the multiple-case study analyses necessary to meet this challenge. After being presented, the practical feasibility, effectiveness and logistics of such a methodology are tested by examining the activities that Vienna has implemented to deliver its smart city development strategy. The results of this pilot study show how the application of the proposed methodology can help smart city researchers codify the knowledge produced from multiple smart city experiences using a common protocol. This in turn allows them to: (1) coordinate efforts when investigating the strategic principles that drive smart city development and test the divergent hypotheses emerging from the scientific literature; (2) share the results of this investigation and hypothesis testing by conducting extensive cross-case analyses among multiple studies able to capture the generic qualities of the findings; (3) gain consensus on the way to think about, conceptualize and standardize the analysis of smart city developments; and (4) develop innovative monitoring and evaluation systems for smart city development strategies by reflecting upon the lessons learned from current practices.
\end{abstract}

Keywords: smart city; urban innovation; sustainable urban development; research methodology; Vienna

\section{Introduction}

Mora et al. $(2017 ; 2018)$ and Komninos and Mora (2018) reveal the presence of a deeply rooted division in the underlying structure of the smart city research field and show that such a division surfaces as a set of dichotomies that question how smart city development ${ }^{1}$ should be approached. Their research demonstrates that these dichotomies present themselves as divergent hypotheses on what strategic principles need to be considered when designing and implementing the actions required to support the development of smart cities. It also goes on to suggest that this division generates uncertainty over the way ahead and a knowledge gap that needs to be closed in order for smart cities to move forward as a set of groundbreaking urban innovation practices able to demonstrate the "transformative and disruptive role technology [has] in solving urban issues" and supporting urban sustainability (March 2016).

This paper considers multiple-case study research with a deductive approach as one of the

\footnotetext{
${ }^{1}$ In this article, smart city development is considered as an ICT-driven approach to urban sustainability and smart cities are defined as follows: cities in which issues limiting sustainable urban development are tackled by means of ICT-related solutions (Mora et al. 2018). The term 'city' is here used to refer to any type of urban areas, irrespective of their population size.
} 
most suitable method for testing the divergent strategic principles for smart city development that each dichotomy stands for. The ambiguity surrounding smart city research demonstrates that a critical synthesis of the literature produced to date is missing and the empirical knowledge needed to close the gap that currently exists between theory and practice have not been generated yet. Multiple-case study analyses able to investigate and compare the smart city phenomenon under different conditions are required to bring about such a knowledge and advise on what strategic principles drive smart city development, and the use of a common research design can help smart city researchers to coordinate their efforts towards the achievement of this common objective ${ }^{2}$.

Following such a line of reasoning, this paper introduces a research methodology that can be deployed for conducting large-scale multiple-case study analyses of smart city development strategies and acquire the scientific knowledge necessary to overcome the dichotomous nature of smart city research. In addition, it reports on the results of a pilot study which is instrumental in examining the practical feasibility, effectiveness and logistics of the proposed methodology. During the pilot study, the smart city development strategy implemented by the city of Vienna is examined.

The paper is structured in four sections. The first one provides an extensive discussion of the four dichotomies that Mora et al. $(2017 ; 2018)$ have identified. This discussion is based on the review of the most recent literature on smart cities and offers an understanding of the division within smart city research. The design of the methodology proposed for testing the divergent strategic principles that each dichotomy puts forward is presented within the second section, while its functioning is examined in the third, which reports on the results of the pilot study and the authors' experience of conducting it. Structuring the paper in this fashion makes it possible to show how the proposed methodology can be deployed and how its components work together, ensuring its practical feasibility and effectiveness. The logistics of the pilot study also allow the singular nature of this case study to be addressed by: (1) evaluating the sustainability of the research process and its practicability; (2) providing recommendations which are based on direct experience; (3) detecting practical issues and limitations that may affect a larger sample of case study analyses and provide possible solutions. These three aspects are discussed in the last and conclusive section of the paper, which addresses the lessons learned from the pilot study.

\section{The dichotomous nature of smart city research}

Transforming urban areas into smart cities is an ambition that local and regional governments are trying to realize by developing strategies that make it possible to tackle urban sustainability issues by means of ICT solutions. Cases of smart city development strategies can be found in communities all over the world and their developments have been captured by an increasing number of studies. Some of these studies and the smart city cases they examine are listed in Table 1.

However, despite a growing interest in smart cities and almost three decades of literature analyzing their development, a clear explanation of what needs to be done in order for urban environments to succeed in designing and implementing strategies for supporting smart city transformations is still missing. In the literature currently available, different development paths can be identified (Mora et al. 2017; 2018; Komninos and Mora 2018), whose presence generates uncertainty on how to approach smart city development. This is because these paths suggest strategic principles that are divergent in nature, making it difficult to establish whether

\footnotetext{
${ }^{2}$ Case study research can be approached by using either single- or multiple-case studies. However, as Yin (2009) and Eisenhardt (1989) suggest, multiple-case study analyses provide broader opportunities to generalize the theoretical prepositions under investigation than examinations based on single-case studies.
} 
smart city development should be based on a: (1) Technology-led or holistic strategy; (2) Double or quadruple-helix model of collaboration; (3) Top-down or bottom-up approach; (4) Monodimensional or integrated intervention logic. The questions arising from each dichotomy mark a knowledge gap that current research on smart cities is unable to close, and which can be demonstrated by reviewing the literature produced to date (see Table 2).

When trying to define whether a successful smart city development strategy is technology-led or holistic, smart city researchers provide two different answers (Niaros 2016; Mora et al. 2017). On the one hand, according to the literature produced by ICT companies such as IBM, Cisco Systems, Siemens, ABB, Hitachi and Fujitsu, smart city development is driven only by information and communication technologies. On the other hand, a large body of literature suggests this vision is inadequate to support smart city development because it conceives smart cities as technological objects rather than complex socio-technical systems in which technological development need to be aligned with human, social, cultural, economic and environmental factors.

In addition, as pointed out by Soderstrom et al. (2014), McNeill (2016) and Paroutis et al. (2014), ICT companies also suggest smart city development strategies require a narrow collaborative model in which the interaction is only between service providers selling their smart city solutions to local governments. However, a large number of researchers consider the double-helix structure of this collaborative model unable to provide the intellectual capital which is necessary to drive smart city development. Their research calls for a much more open and inclusive collaborative ecosystem based on a quadruple-helix structure ${ }^{3}$ where all the city stakeholders representing research, industry and government are involved, along with civil society organizations and citizens ${ }^{4}$.

This division also surfaces in relation to the third question: is the most suitable approach for developing smart cities top-down or bottom-up? In the first case, the city government defines both a long-term vision and a strategic framework for supporting smart city development. Whereas the bottom-up approach is deregulated, based on self-organization and founded on grassroots movements. In addition, it puts civil society in the driving seat, suggesting the direct involvement of the people in the development of ICT-driven solutions for urban sustainability and their integration in the urban environment is what determines whether strategies are successful or not. The researchers championing the bottom-up approach also highlight the importance of a radical shift from top-down urban innovation processes and movement towards an open and bottom-up process of urban innovation.

The last dichotomy concerns the intervention logic to be considered when implementing smart city development strategies. According to Manville et al. (2014), smart city development requires an integrated and multi-dimensional approach and a successful smart city development strategy covers a large number of policy domains. This assumption is in line with the assessment system that Vienna University of Technology, University of Ljubljana and Delft University of Technology applied in 2007 to compare a large group of medium-sized European cities and evaluate their performance as smart cities. The following six domains were considered: living; economy; people; environment; mobility; and governance (Giffinger et al. 2007). This multidimensional intervention logic is also supported by IBM Corporation (2017a; 2017b) and Cisco Systems (2016a; 2016b) and their operating systems for smart cities: comprehensive ICT

\footnotetext{
${ }^{3}$ The quadruple-helix collaborative model is driven by the university-industry-government relations composing the triple-helix model (Etzkowitz and Leydesdorff 2000) and adds civil society, i.e. civil society organizations and citizens, as fourth element of the collaborative ecosystem (Arnkil et al. 2010; Cavallini et al. 2016).

${ }^{4}$ United Nations (1998), Food and Agriculture Organization (2013), World Economic Forum (2013) and European Commission (2014) define civil society organizations as a broad category which encompasses non-governmental organizations (NGOs), community groups, charities, trusts, foundations, advocacy groups, faith-based organizations and national and international non-state associations.
} 
platforms that integrate a collection of digital solutions and applications for improving the management of systems for energy and utilities, parking, environmental protection, safety and security, transportation, education and healthcare. In contrast to this, the European Commission promotes a mono-dimensional vision of the smart city, which is described as a low-carbon and resource efficient urban environment fully committed to invest in IT solutions for smart transport, smart buildings and smart grids.

This extensive literature review exposes the hidden contradictions of the debate on smart cities and the four dichotomies that the research conducted into the subject has generated. Each dichotomy surfaces from divergent hypotheses concerning what strategic principles drive smart city development. These hypotheses are listed in Table 3 and the scientific knowledge required to empirically test their validity can be acquired by conducting multiplecase study analyses. The following section provides a comprehensive and thorough description of the methodology that this paper proposes to organize and carry out such analyses.

\section{A research methodology for investigating smart cities}

Case study research involves the empirical investigation of a current phenomenon within its real-life context and can be applied to meet four different purposes: (1) to provide descriptions; (2) to build new theories; (3) to refine existing theories; and (4) to test the validity of existing theories (Eisenhardt 1989; George and Bennett 2005; Robson 1993; Yin 2009). The research methodology that this paper proposes focuses attention on the last approach: its aim is to activate a theory-testing process able to assess the validity of the divergent hypotheses emerging from each dichotomy by means of multiple-case study analyses of smart city development strategies. This methodology is built on the most relevant literature describing how case study research should be approached (Creswell 2009; Eisenhardt 1989; Eisenhardt and Graebner 2007; George and Bennett 2005; Gerring 2004; Gibbert et al. 2008; Miles and Huberman 1994; Patton 1990; Robson 1993; Seawright and Gerring 2008; Shakir 2002; Stake 1978, 1995, 1998; Yin 2009; 2012) and is composed of three phases: (1) Multiple-case study selection; (2) Data collection; and (3) Data processing and analysis.

\subsection{Phase 1: Multiple-case study selection}

The selection of the appropriate cases is key to a successful multiple-case study analysis. Considering the purpose of this study, the selection process needs to rely on a theoretical sampling approach and not a random selection. Theoretical sampling means that case studies, as experiments conducted in a laboratory, are not randomly sampled from a population, but "chosen for the likelihood that they will offer theoretical insight" (Eisenhardt and Graebner 2007: 27).

Starting from an initial population of cities in which a strategy for supporting smart city development has been designed and implemented, the researcher is required to find and focus attention on extreme cases: unusual manifestations of the smart city phenomenon, which show either outstanding success or failure in approaching such development. These cases are the most suitable to confirm or disprove the initial hypotheses by observing what strategic principles have driven the selected cities. The selection of extreme cases depends on how the researcher wants to approach the replication logic. The available options are the followings: (1) Literal replication: the cases are chosen due to their similar settings and are expected to provide similar results; and (2) Theoretical replication: the selected cases have different settings and variations are expected in the analysis' results.

The first approach is based on the selection and comparison of either (1) cities that have successfully approached smart city development and the ICT-driven approach to urban sustainability it promotes, or (2) cities in which the transition process has proven to be unsuccessful. The literal replication is exemplified by Ornetzeder and Rohracher (2013), who investigate 
the internal dynamics and structural conditions necessary to develop successful grassroots innovations in the fields of energy and transport. The investigation is conducted by comparing three outstanding cases of sustainable grassroots innovations. Aschemann-Witzel et al. (2017) propose something similar in their investigation into key success factors in initiatives designed to reduce consumer-related food waste. Addition examples are provided by Mora and Bolici (2016; 2017) and Bolici and Mora (2015), wherein the selection of two leading cases of smart cities make it possible to outline a preliminary roadmap describing the design and implementation process of smart city development strategies.

By following a theoretical replication logic, attention is instead focused on both types of extreme cases and the researcher tests its initial hypotheses by comparing successful and unsuccessful samples. For example, Li et al. (2012) investigate the role of public-private partnerships in residential brownfield redevelopment by analyzing two case studies that have produced opposite results. This approach has also helped Brunia et al. (2016: 30), who compares workspaces with opposite employee satisfaction scores in order to explore what factors explain "the high or low percentages of satisfied employees in offices with shared activity-based workplaces".

Both approaches are considered as suitable for this research methodology, as they are complementary in nature. However, despite the approach chosen for conducting the case study analysis, it is important to note that the multiple-case study selection process and the number of replications always determine the external validity of the analysis and to what extent the findings can be generalized. The number of replications depends upon the certainty the researcher wants to achieve and "the greater certainty lies with the larger number of cases" (Yin 2009: 58). Research by Eisenhardt (1989) suggests a number of cases between four and ten is ideal to have a good basis for analytical generalization ${ }^{5}$.

In addition, analytical generalization is also affected by two contextual conditions: the geographical distribution of the selected cases and their size ${ }^{6}$. A more heterogeneous sample determines a broader generalization of the results. For example, Calzada (2017) investigates the governance strategies of leading smart city transformations by comparing four European cities located in two different countries: Glasgow and Bristol in the United Kingdom and Barcelona and Bilbao in Spain. This approach makes it possible to improve the common understanding of such effects in Europe, but additional research is required to test whether the findings are of wider significance because they also apply to other territorial contexts.

\subsection{Phase 2: Data collection}

The researcher follows a replication logic and subjects all the selected cases to the same analytical process, which starts with the data collection phase. To establish what strategic principles have led the cities towards becoming successful or unsuccessful examples of smart cities, two databases are required. The first one includes a list of all the activities undertaken by each city to implement the smart city development strategy, which shall be organized and classified in four categories:

\footnotetext{
${ }^{5}$ Case study research does not allow for statistical generalization but analytical generalization. As Yin (2009: 38) points out, in case study research "the mode of generalization is analytic generalization, in which a previously developed theory is used as a template with which to compare the empirical results of the case study. If two or more cases are shown to support the same theory, replication may be claimed. The empirical results may be considered yet more potent if two or more cases support the same theory but do not support an equally plausible, rival theory".

6 For the selection of the cases, we suggest using the classification system developed by the European Commission and Organisation for Economic Co-operation and Development (OECD), in which cities are divided by number of inhabitants. The classification system is composed of the following six categories: $S(50,000$ 100,000); M (100,000 - 250,000); L (250,000 - 500,000); XL (500,000 - 1,000,000); XXL (1,000,000 - 5,000,000); Global cities (More than 5,000,000) (Dijkstra and Poelman 2012).
} 
A. Community building: activities supporting the construction of an open and inclusive collaborative environment able to support the design and implementation of the smart city development strategy. This is done by: raising citizen engagement in the smart city field; stimulating user-driven innovation and community-led urban development; increasing public awareness and digital literacy; informing the city's stakeholders; and improving their level of understanding about smart city development and the benefits it can generate;

B. Strategic framework: activities aiming to develop the city's strategic framework for guiding and regulating smart city development. These activities' output includes: (1) action plans, programmes, guidelines, roadmaps, recommendations, governmental acts and policy documents; (2) measures proposing standards and technical requirements, along with assessment methods; and (3) workgroups managing the general course of the smart city development strategy's operations;

C. Services and applications: activities which allow new ICT services and applications to be integrated within the city;

D. Digital infrastructure: activities aiming to develop the technological infrastructure necessary to use and benefit from the available ICT services and applications. Examples of activities include the integration of urban operating systems and the construction or extension of high-speed broadband networks and public Wi-Fi networks.

This classification system makes it possible to group together all the activities according to the objectives and outcomes towards which efforts are directed. In case of activities producing outcomes that belong to multiple categories, they need to be included in more than one group. By analyzing the percentage of activities belonging to each group, the researcher will be able to determine whether the smart city development strategies under investigation are: (1) holistic or technology-led (Dichotomy 1); and (2) developed by means of either a top-down or bottomup approach (Dichotomy 2).

The activities belonging to the category " $\mathrm{C}$. Services and applications" shall then be assigned to one or more application domains to investigate the smart city development strategy's intervention logic (Dichotomy 4). These activities allow the integration of new digital solutions within the urban environment and can be classified according to the objectives pursued through their implementation. The classification system is composed of 11 application domains, which are described in Table 4 and selected by merging the classification systems for smart technologies proposed to date (Giffinger et al. 2007; Manville et al. 2014; Neirotti et al. 2014; Reviglio et al. 2014; Cisco Systems 2016a; 2016b; $)^{7}$. This typology makes it possible to build a classification system as broad as possible.

After classifying all the activities, the researcher shall focus attention on the structure of each smart city development strategy's inter-organizational collaborative network (Dichotomy 3). The aim is to build a second database describing such a network and establish whether the model of collaboration is based on a double or quadruple-helix approach. To meet this aim, the organizations that have collaborated in developing the activities previously mapped need to be identified and classified. In addition, each activity shall be analyzed to establish whether citizens have been involved in the implementation process. The following classification system is provided to group the organizations by type:

1) Research: universities and other research and educational institutions;

2) Industry: businesses which are involved in consultancy activities and/or in the distribution of goods and services;

3) Government: local, regional and national governmental authorities, along with their majority-owned subsidiaries and external agencies;

4) Civil Society: civil society organizations;

${ }^{7}$ See also IBM (http://www-03.ibm.com/ibm/history/ibm100/us/en/icons/smarterplanet). 
5) Other: organizations that do not belong to the previous categories or where the information necessary to complete the classification is not available.

These classification systems allow for the activities and organizations to be mapped and analyzed by cross-referencing the qualitative data extracted from multiple sources. Digital records reporting on the smart city development strategy under investigation and produced by the city government should be considered as primary sources. These include the following examples: agendas; minutes of meetings; press releases; news and newsletters; conference presentations; conference speeches obtained from either presentations' notes or videos of the events; reports; brochures; governmental acts; policy papers and documents; and webpages. Additional data shall also be acquired from digital records produced by organizations that are either collaborating with the city government in implementing the city's smart city development strategy, or not involved but interested in providing data describing such a strategy. These sources are to be considered as secondary and can include, for example, reports produced by consultancy firms, news and articles published in online magazines and any type of scholarly publications. This approach strengths the quality of the research process because the multiple-case study analysis is conducted by combining data and information which are extracted from multiple sources and provided by both internal and external observers ${ }^{8}$.

Primary and secondary sources can be found by conducting multiple keyword search queries which aim to scan the World Wide Web. The following search string is suggested: "[name of the city under investigation] smart city". If the case study is located in a non English-speaking country, the search string should be adapted in accordance with the local language. For example, in the case of Barcelona, data items reporting on the city's smart city development strategy frequently use the term "ciudad inteligente" instead of "smart city" (Ajuntament de Barcelona 2012; 2013).

\subsection{Phase 3: Data processing and analysis}

Coding is suggested as a method to organize the large volume of unstructured qualitative data collected from the data items and facilitate the identification and classification of both activities and organizations, along with their progressive analysis. "Coding is how you define what the data you are analyzing is about. It involves identifying and recording one or more passages of text or other data items such as the part of pictures that, in some sense, exemplify the same theoretical or descriptive idea. Usually, several passages are identified and they are then linked with a name for that idea - the code. Thus, all the text and so on that is about the same thing or exemplifies the same thing is coded with the same name" (Gibbs, 2007: 38).

The coding process shall be conducted by following the procedure suggested by Eisenhardt (1989), Gibbs (2007), Robson (1993) and Strauss and Corbin (1990). Qualitative data analysis and research software programs, such as Atlas.ti, NVivo and QDA Miner, can be deployed as supporting tools. After being collected, the digital records need to be reviewed repeatedly to identify the activities that every city selected as case study has implemented to enable smart city development. Each activity shall be assigned a code, so as the sections of text or other data items describing the following attributes: objectives of the activity; generated or expected outcomes; and organizations involved in its development ${ }^{9}$.

\footnotetext{
8 Interviews can be considered as an additional source of information, but it is important to remember that this data collection method requires a great deal of resources and preparation, key informants need to be selected whit precision and a protocol needs to be designed to guarantee a high degree of data reliability (Robson 1993; Yin 2009). Therefore, we suggest conducting interviews only when indispensable, in particular whether: (1) digital records are scarce or do not provide sufficient data on the programme of activities of the smart city development strategies under investigation; or (2) further validation of data through cross verification is needed.

${ }^{9}$ Data items different from texts include pictures, maps, technical drawings and specific sections of audio and video files.
} 
The coding process is expected to result in a detailed report in which the activities of each city are listed and the data necessary to study them is presented in a structured and well-organized form. This data shall then be used to populate the two databases and acquire the knowledge necessary to test the divergent hypotheses emerging from the four dichotomies.

\section{Pilot study: testing the research methodology}

A small-scale preliminary study is conducted to assess the practical feasibility, effectiveness and logistics of the proposed methodology. This makes it possible to reveal practical issues and limitations, and propose changes able to solve them. In addition, this pilot study offers the possibility to show researchers how the research methodology can be deployed by way of a practical example.

The pilot study is split in three phases. During the first phase, the strategy for multiple-case study selection is verified by simulating the sampling process of a multiple-case study analysis that: (1) focuses attention on large European cities (population between 500,000 and $5,000,000$ inhabitants $)^{10}$; and (2) is based on a literal replication logic. The sampling process results in the identification of ten extreme cases: large European cities that have successfully approached the implementation of strategies for supporting smart city development. One of these extreme cases is then selected to run the second and third testing phases, in which the approach proposed for collecting, processing and analysing the data is examined.

\subsection{Testing phase 1: Multiple case study selection}

An initial population of cities in the selected range of inhabitants and belonging to the European Union's Member States is defined by combining the census statistics of each country ${ }^{11}$. In accessing such data, 60 candidate case studies are identified, and the followings are subsequently selected as extreme cases: Amsterdam in the Netherlands; London, Birmingham, Glasgow and Manchester in the United Kingdom; Copenhagen in Denmark; Barcelona and Madrid in Spain; Vienna in Austria; and Helsinki in Finland. These ten cities are selected due to their success in the field of smart cities and heterogeneous geographical distribution. Together, they cover six different European countries, and this provides the basis for a broad generalization of the results.

The success of each candidate case study in the field of smart city development is evaluated by means of an online search phase, which is conducted to identify and review the literature reporting on: (1) comprehensive comparative analyses of smart city cases and smart city rankings in which one or more candidate case studies are shown to be leading examples; and (2) competitions in which these cities have been awarded for their smart city development strategies. The data resulting from this search supports the identification of the ten above-mentioned extreme cases:

- After comparing infrastructural, social and economic factors characterizing a large sample of cities, Kotkin (2009) has included Amsterdam in the top ten world's smart cities;

- Amsterdam, Copenhagen and Vienna are respectively among the winners of the World Smart Cities Awards 2012, 2014 and 2016. In addition, along with Barcelona, Amsterdam is also one of the finalists at the 2015 edition $^{12}$;

\footnotetext{
10 In the classification system developed by European Commission and OECD, cities with a population between 500,000 and 5 million inhabitants belong to the XL and XXL categories (Dijkstra and Poelman 2012).

11 The census statistics are presented in the Appendix $A$.

12 The World Smart Cities Awards is a competition that the Smart City Expo World Congress organizes annually to identify the most ambitious strategies, the most advanced projects and the most innovative initiatives around the world fostering the development of the smart city concept. The complete lists of winners and finalists of each edition of the World Smart Cities Awards are available on the Smart City Expo World Congress' website: http://www.smartcityexpo.com
} 
- The Intelligent Community Forum (ICF)'s team of analysts has named Barcelona as one of the best Smart Communities of 2012, recognizing the city's leadership role in supporting urban development and innovation by leveraging the potential of ICT solutions and infrastructures ${ }^{13}$;

- The Amsterdam's smart city development strategy has been selected as a "Benchmark of Excellence" by the European Commission and described as a best practice to be replicated in other urban contexts (Velthausz 2011);

- Amsterdam has been awarded the European City Star Award 2011 by the European Commission, which has highlighted the capability of its smart city development strategy to demonstrate how cities can be successful in bringing together public parties, private organizations and citizens in order to take advantage of ICT for urban development purposes (I amsterdam 2011; Amsterdam Smart City 2011);

- According to the Smart City Index Rankings developed in 2011 and 2012 by IDC (International Data Corporation), Barcelona and Madrid are both among the top five smart cities in Spain (Achaerandio et al. 2011; 2012);

- In a recent study benchmarking Austrian smart cities, IDC (2016) has also included Vienna amongst the most advanced smart city cases;

- The European Commission has nominated Barcelona as the 2014 European Capital of Innovation for its smart city development strategy. According to the jury, this strategy shows how the use of ICT can bring the city government closer to its citizens (European Commission, 2014a);

- According to a new study commissioned by Huawei and conducted by Navigant Consulting (Woods et al. 2016), London, Birmingham, Glasgow and Manchester are the United Kingdom's leading examples of smart cities;

- Vienna heads the Smart City Strategy Index developed by the consulting firm Roland Berger, while Stockholm and Copenhagen are among the top-performing European cities (Zelt et al. 2017);

- Considering the data provided by Manville et al. (2014), the Directorate-General for Internal Policies of the European Parliament has recognized Amsterdam, Barcelona, Copenhagen, Helsinki, Manchester and Vienna as four of the six most successful smart cities in Europe and the most suitable cases for further in-depth analyses.

\subsection{Testing phase 2: Data collection}

The practical feasibility and effectiveness of the data collection, processing and analysis processes are tested by using the case of Vienna, which is randomly selected among the ten extreme cases. This makes it possible to continue with the pilot study and starts searching for the digital records from which to collect the qualitative data necessary to conduct the analysis. The data collection process is composed of a series of searches ${ }^{14}$, each one pursuing a specific aim, in which Google and multiple search strings are deployed:

- Search 1: "Vienna smart city" OR "Wien smart city"

- Search 2: "Vienna smart city" OR "Wien smart city" site:smartcity.wien.gv.at

- Search 3: "Vienna smart city" OR "Wien smart city" site:www.wien.gv.at

- Search 4: "Vienna smart city" OR "Wien smart city" -"www.wien.gv.at" "smartcity.wien.gv.at"

Search 1 is conducted in order to find the main online repositories in which the city government of Vienna stores the digital records reporting on the city's smart city development strategy. The pages displayed by the search engine in response to the query show that the city government's repositories storing most of the data items are the City Council's online information

\footnotetext{
${ }^{13}$ The Intelligent Community Forum is an independent think tank based in New York City. All the information on its Awards Programme and the winners of each edition can be found at: http://www.intelligentcommunity.org

14 The search phase is conducted in April 2016
} 
service (https://www.wien.gv.at) and Smart City Wien, the official website of the Vienna's smart city development strategy (https://smartcity.wien.gv.at).

Both repositories are searched (Search 2 and Search 3) and this makes it possible to detect 365 digital records, which include press releases, news, newsletters, webpages, interviews, conference presentations, reports, posts on social media websites, policy papers and documents and governmental acts. After being identified, every data item has been downloaded and labelled using consecutive numbers. In addition, an excel spreadsheet is created in which the items' Uniform Resource Locators (URLs) are listed in order to check the presence of duplicates, which are eliminated as soon as detected.

This list is then expanded upon by adding 114 new digital records produced by organizations that are either collaborating with the city government in implementing Vienna's smart city development strategy or interested in communicating information describing the programme of activities that have been undertaken. These organizations are consultancy firms, publishing companies, research centers, universities, national and regional governmental authorities and non-governmental institutions, and the digital records they have produced include scholarly publications, articles found in online magazines and newspapers, posts, press releases, reports and videos. These data items are considered as secondary sources and are collected with Search 4, in which Google is asked to automatically eliminate any results from the two city governments' online repositories previously examined.

\subsection{Testing phase 3: Data processing and analysis}

Overall, $99.3 \%$ of the collected digital records are textual documents, while the remaining items are digital videos. Considering the high number of data items, their analysis is conducted by using Atlas.ti as supporting tool. Atlas.ti works with a large range of media, however, in order to be processed, files need to be formatted according to the system's requirements. Therefore, text documents stored in formats different from .txt, .doc, .docx, .odt and .pdf are all converted. On the contrary, no changes are required for the video files.

After being prepared and uploaded onto Atlas.ti, the digital records are reviewed in a systematic way to identify the activities that Vienna has developed to implement its smart city development strategy. Each activity is assigned a code, so as the data items' sections describing the following attributes: objectives of the activity; generated or expected outcomes; and entities involved in its development. The coding process results in a detailed report in which the activities are listed one by one and the data necessary to study them is presented in a structured and well-organized form. The report is generated by using Atlas.ti's output function called Codebook and used to create two databases, in which activities and organizations are classified (see Appendix B and Appendix C). It is important to note that, the information necessary to classify each organization was obtained from their official websites, because the data provided by the digital records was insufficient to complete this task.

With the coding process, 54 activities are mapped (see Figure 1) and their analysis makes it possible to understand how Vienna has approached smart city development and test the validity of the hypotheses each dichotomy stands on.

\section{Dichotomy 1: Technology-led or holistic strategy}

Vienna's smart city development strategy gives equal weight to: (1) the deployment of technological advancements leading to either the resolution or mitigation of urban sustainability issues; and (2) the development of both a collaborative environment and a strategic framework for supporting the deployment of these technological advancements. This strategy is therefore based on a holistic vision of smart cities, which are not considered as technology-only focused systems resulting from the massive combination of sets of interconnected ICT components, 
but socio-technical systems in which technological development is aligned with human, social, cultural, economic and environmental factors.

The accuracy of this statement is evidenced by the data in Figure 2, in which the percentage of activities by group of categories is compared and appears to be balanced. The first group includes those activities belonging to at least one of the first two categories, i.e. "A. Community building" and "B. Strategic framework", which both focus attention on the non-technological factors of smart city development. For example, with the European projects CLUE, TRANSFORM and Urban Learning, Vienna has improved its capability to deliver policy and programs for supporting the deployment of ICT solutions able to reduce carbon emissions (Brandt et al. 2014; Hartmann et al. 2015; Hemis et al. 2017; CLUE Project Partners 2014). In collaboration with a consortium composed of 28 partners, which includes city governments, businesses and universities, Vienna has also launched Smart Together, a project aiming to test new approaches for fostering user-centric innovation, collaboration and citizen engagement in smart city development ${ }^{15}$.

On the contrary, the second group of activities include projects and initiatives in which the deployment of ICT services, applications and infrastructures within the urban environment is among the objectives or the only objective. Examples of technological solutions and infrastructures include: decision-supporting tools for managing urban energy and mobility systems (Bednar et al. 2016; Marguerite et al. 2016); electric vehicles, charging infrastructures and info-mobility systems (Wiener Modellregion and Climate and Energy Fund 2014); a large-scale network of $\mathrm{Wi}-\mathrm{Fi}$ access points in public spaces and leisure areas to provide citizens and tourists with location-based information and free of charge access to the Internet; mobile apps allowing the city government to receive feedback and send up-to-date information and instructions on how to proceed in case of dangerous situations; and QR codes for accessing digital contents related to local facilities via mobile devices ${ }^{16}$.

\section{Dichotomy 2: Top-down or bottom-up approach}

Vienna's smart city development strategy is holistic and keeps a balance between top-down and bottom-up approaches. The city government is the most active organization belonging to the smart city ecosystem of Vienna and has contributed to develop about $50 \%$ of the total activities (see Appendix C). This means that Vienna's smart city development is boosted by a significant number of bottom-up activities and, what is more, the analysis of the objectives and outcomes related to the work undertaken by the city government demonstrates that it is clearly aimed at promoting this bottom-up development process. The city government provides leadership and its actions are oriented towards the construction of: (1) a decentralized development process; (2) an open, inclusive and cohesive collaborative ecosystem; and (3) the strategic framework for regulating the smart city transformation of the entire city and bringing the different organizations belonging to this ecosystem into a harmonious and efficient relationship.

To achieve this aim, the city government:

- sets up a participatory process for developing the Smart City Wien Framework Strategy, i.e. a strategic document that lays down Vienna's guidelines for smart city development. This document provides a long-term vision that extends to 2050 and establishes what objectives need to be achieve and the expected results. In addition, it identifies the application domains to focus attention on and describes the governance and monitoring systems that shall be adopted and the strategic principles to follow.

\footnotetext{
${ }^{15}$ Additional information can be found in the project's official website: http://smarter-together.eu.

${ }^{16}$ Additional data on mobile applications and Wireless LAN hotspots currently available in Vienna is provided by the city government at https://www.wien.gv.at.
} 
The use of a participatory approach ensures the Framework Strategy represents a single vision that city stakeholders all agree on (City of Vienna 2014);

- collects ideas, comments and feedback about the city's ICT requirements from public and private sector organizations and citizens in order to develop a Digital Agenda with projects for handling Vienna's most pressing urban challenges (Heissenberger and Schuhböck 2015);

- increases Vienna's know-how on urban technologies and smart city development by collaborating in delivering new planning and operational tools, recommendations, guidelines, standards and technical requirements, and evaluation and assessment methods ${ }^{17}$.

- $\quad$ assigns the role of Smart City Wien Agency to TINA Vienna $\mathrm{GmbH}^{18}$, which becomes "the central coordination point for all internal and external stakeholders. It should cover the areas of coordination, stakeholder management, inquiry management and communication and would record, evaluate and initiate projects on behalf of all relevant partners within and outside the City of Vienna. The objective lies in the interdisciplinary promotion of networking between municipal administration, research, business and industry" (City of Vienna 2014: 88);

- collaborates in organizing forums, conferences, workshops and meetings dealing with smart city development in order to: generate interest; inform the community; engage new stakeholders and make the collaborative ecosystem larger; stimulate collaboration; and raise public awareness of the potential benefits ICTs can produce in urban environments (City of Vienna, 2016a; Digital City Wien 2015; 2016);

- makes public data freely accessible to support developers interested in building new applications and digital services ${ }^{19}$.

\section{Dichotomy 3: Double or quadruple-helix model of collaboration}

The smart city collaborative ecosystem of Vienna is analyzed and graphically visualized by using the open-source software Gephi. The result is the network illustrated in Figure 3, in which, the organizations mapped during the coding process are represented as nodes with a diameter that is directly proportional to the number of activities they have worked on. Every edge connects the organizations which have collaborated in implementing at least one activity. The stronger the degree of collaboration between two organizations, the higher the thickness of the edge connecting them. Colors are assigned according to the organization types.

The data describing the networks' structure shows that Vienna has approached smart city development by means of a triple-helix collaborative model: the collaboration between industry, government and research is the engine behind Vienna's smart city development strategy. With participation at $56 \%$, businesses are the most active organizations and are followed by institutions for education and research and governmental authorities, which both represent approximately $19 \%$ of the collaborative network. The remaining $4 \%$ are civil society organizations, which are by far the less represented organization type.

However, despite this data, it is important to note that a number of activities suggest Vienna has made an effort to strengthen the participation possibilities of civil society by increasing citizens' active involvement in the implementation process of its smart city development strategy (see Figure 4). This intent is clearly expressed in the strategic frameworks that the city government has developed to guide and regulate the development of Vienna as a smart city

\footnotetext{
17 See the following projects: CityOpt (http://www.cityopt.eu); TRANSFORM (http://urbantransform.eu); PUMAS (www.pumasproject.eu); TRANSFORM+ (http://www.transform-plus.at); EU-GUGLE (http://eu-gugle.eu); and INNOSPIRIT (http://www.innospirit.org).

18 TINA Vienna $\mathrm{GmbH}$ is part of Wien Holding $\mathrm{GmbH}$ (2012), a holding company of the City of Vienna that carries out community tasks.

19 Data are provided through the online platform Open Government Wien (https://open.wien.gv.at/site/open-data/).
} 
(City of Vienna 2014). For example, the city government has invited Vienna's citizens to take part in the planning phase of the smart city development strategy and support the production of the strategic framework by attending a series of stakeholders' forums, along with representatives from universities, governmental authorities, the business sector and civil society organizations. These forums have been organized regularly and conceived as discussion events for exchanging ideas and ensuring greater transparency, participation and collaboration in the smart city field (Hofstetter and Vogl 2011; Climate and Energy Fund 2013; City of Vienna et al. 2011; 2013; City of Vienna 2012; 2013a; 2013b; 2014; 2016).

In addition, a number of projects have activated collaborative processes in which citizens are asked to participate in the design and testing phases of ICT solutions and infrastructures to be deployed in the urban environment. The aim is to improve the capability of ICT to meet local community's needs. This is the case of Smarter Together and Smart Cities Demo Aspern, in which Living Labs are used as collaborative platforms for attracting high public attention and foster user-centric innovation (Aspern Smart City Research 2015; Muhlmann 2017) ${ }^{20}$. All of this provides evidence of an attempt to move from a triple to a quadruple-helix collaborative model.

\section{Dichotomy 4: Mono-dimensional or integrated intervention logic}

The data obtained from the analysis of the activities belonging to the category "C. Services and applications" shows that Vienna has adopted an integrated intervention logic and its smart city development strategy covers a mix of application domains (see Figure 5). The city's interest in smart city development is mainly oriented towards smart transport, smart building and smart grid solutions for low-carbon and energy efficient urban environments. Most of the ICT services and applications supporting Vienna's smart city transformation are deployed to fight climate change and boost energy efficiency in mobility and transport (C.05), buildings and city districts (C.06) and power infrastructures (C.01).

This approach is aligned with the European Commission's interpretation of smart cities. However, Vienna's smart city development strategy makes a significant effort to extend such an interpretation by seeking to use digital technologies for addressing additional sustainability issues related to other policy domains. For example, technological solutions are brought into action to: improve the management of natural resources other than energy, such as air, waste and water; stimulate the use of public transports by providing citizens with real-time information; stimulate social inclusion and citizens collaboration by offering up-to-date overviews of where co-design activities are implemented in Vienna and opening public data; and increase the quality of assistance services for elderly people by helping them to easily access the online world ${ }^{21}$.

\section{Discussion and conclusions}

Overcoming the dichotomous nature of smart city research is fundamental in order to provide cities with a clear understanding of how smart city development should be approached, and to support them in delivering the programme of activities needed to enable such a development. This paper introduces a research methodology for conducting the deductive multiplecase study analyses necessary to meet this challenge. In addition, it reports on the practical feasibility, effectiveness, logistics and replicability of this methodology by analyzing the implementation process of the smart city development strategy proposed by Vienna.

\footnotetext{
20 For further information, see also: 1) the website of the Austrian Institute of Technology (AIT), which has collaborated in delivering the project Smart Cities Demo Aspern (https://www.ait.ac.at/en/research-fields/smartgrids/projects/smart-cities-demo-aspern); 2) the official website of the project Smarter together (http://smartertogether.eu).

${ }^{21}$ See the following projects: CO2 Neutrale; SternE; SeniorTab; Citybike Wien; E-Taxis; SMILE; AnachB; Wien.at live-App; Open Government Data; and Wien Gestalten (https://smartcity.wien.gv.at).
} 
The results of the pilot study show how the proposed research methodology can be deployed to capture and codify the knowledge produced from multiple smart city experiences. This common protocol makes it possible for smart city researchers to: (1) coordinate efforts in investigating which strategic principles drive smart city development and test the divergent hypotheses emerging from the scientific literature; (2) share the results of this investigation and hypothesis-testing by conducting extensive cross-case analyses among multiple studies able to capture the generic qualities of the findings; and (3) collaborate in developing a platform able to generate agreement over the way to think about, conceptualize and standardize the analysis of smart city developments. The standard of reporting that this methodology lays down also makes it possible to account for and make transparent the transformation that cities undergo in the process of becoming smart. This makes it easier for researchers to capitalize on the lessons learned from extreme cases and develop new and innovative monitoring and evaluation systems for assessing the operational value of smart city development strategies.

This study clearly demonstrates that smart cities emerge from a programme of associated activities and, by adopting a reverse engineering approach, these programmes can be deconstructed into building blocks whose analysis enables the structure of any smart city development strategy to be interpreted. This is the rationale behind the research methodology for multiple-case study analyses that this paper reports on and whose validity, effectiveness and replicability are demonstrated by the results of the pilot study.

The pilot study reveals the strategic principles that Vienna has decided to choose in order to enable smart city development. These principles have allowed Vienna to first address the dichotomous nature of smart city research and overcome the ambiguity surrounding the methodology driving smart city development. This is achieved by:

1) Embracing a holistic vision of smart cities, that are considered as socio-technical systems in which technological development is aligned with human, social, cultural, economic and environmental factors;

2) Balancing top-down and bottom-up approaches;

3) Instituting the industry-government-research relationships of the triple-helix collaborative model, while making efforts to strengthen the participation of civil society and progressively moving towards a quadruple-helix model of stakeholder engagement;

4) Assembling an integrated intervention logic that cuts across the multitude of application domains which smart city development represents.

Finally, in terms of logistics, the pilot study clearly shows that the sampling approach, data collection and analytics of the protocol are all adequate, as well as the classification system of smart city activities that have been deployed. It also demonstrates that samples are available when looking for extreme cases of smart cities and the literature reporting on development strategies can provide a great deal of qualitative data able to support comprehensive analytical processes. In addition, it is important to point out that no relevant issues serving to raise questions as to the value of the protocol have been detected when conducting the pilot study. However, researchers need to be aware that the coding process is particularly time consuming and resource intensive, because it requires a systematic analysis of qualitative data which is not only large in scale, but also complex to approach in terms of content analysis. The use of digital supporting tools (Atlas.ti) has been fundamental to manage this phase of the analysis and maintain a chain of evidence supporting the progressive identification of new activities. The contribution of multiple researchers in coding the activities is also extremely helpful when conducting the content analysis, because this reciprocal exercise makes it possible to check the data items in rotation and improve the quality of the coding process.

\section{References}


ABB, ABB Power and Automation: Solid Foundations for Smart Cities (Zurich: ABB, 2013) $<$ http://new.abb.com/docs/default-source/smart-grids-library/abb_smart_grids_white_paper_2013.pdf?sfvrsn=2> Accessed April 5, 2014.

ARUP, Global Innovators: International Case Studies on Smart Cities (London: Government of the United Kingdom - Department for Business, Innovation and Skills, 2013) <https://www.gov.uk/government/uploads/system/uploads/attachment_data/file/249397/bis-13-1216-global-innovators-international-smart-cities.pdf> Accessed September 8, 2016.

R. Achaerandio, G. Gallotti, J. Curto, R. Bigliani, \& F. Maldonado, Smart Cities Analysis in Spain (Framingham, MA: IDC, 2011) <http://www.idc.com/getdoc.jsp?containerld=EIRS56T> Accessed August 6, 2014.

R. Achaerandio, J. Curto, R. Bigliani, \& G. Gallotti, Smart Cities Analysis in Spain 2012 - the Smart Journey (Framingham, MA: IDC, 2012) <http://www.portalidc.com/resources/white_papers/IDC_Smart_City_Analysis_Spain_EN.pdf> Accessed August 6, 2014.

Y.A. Aina, "Achieving Smart Sustainable Cities with GeolCT Support: The Saudi Evolving Smart Cities," Cities: The International Journal of Urban Policy and Planning 71 (2017) 49-58.

S. Alawadhi, A. Aldama-Nalda, H. Chourabi, R.J. Gil-Garcia, S. Leung, S. Mellouli, T. Nam, T.A. Pardo, H.J. Scholl, \& S. Walker, "Building Understanding of Smart City Initiatives," in H.J. Scholl, M. Janssen, M.A. Wimmer, C.E. Moe, \& L.S. Flak, eds., Electronic Government: 11th IFIP WG 8.5 International Conference, EGOV 2012, Kristiansand, Norway, September 3-6, 2012. Proceedings (Berlin: Springer, 2012) 40-53.

V. Amato, L. Bloomer, A. Holmes, \& S. Kondepudi, Government Competitiveness Drives Smart+connected Communities Initiative (San Jose, CA: Cisco Systems, 2012a) <http://www.smartconnectedcommunities.org/docs/DOC-2174> Accessed January 4, 2013.

V. Amato, L. Bloomer, A. Holmes, \& S. Kondepudi, Using ICT to Deliver Benefits to Cities by Enabling Smart+Connected Communities (San Jose, CA: Cisco Systems, 2012b) <http://www.smartconnectedcommunities.org/docs/DOC-2150> Accessed January 4, 2013.

V. Amato, S. Kondepudi, \& A. Holmes, Transforming Communities with Smart+connected Services (San Jose, CA: Cisco Systems, 2012c) <http://www.smartconnectedcommunities.org/docs/DOC2129> Accessed January 4, 2013.

Amsterdam Smart City, Smart Stories (Amsterdam: Amsterdam Smart City, 2011) <https://issuu.com/amsterdamsmartcity/docs/smart_stories> Accessed August 5, 2016.

J. Anderson, D. Fisher, \& L. Witters, Getting Smart About Smart Cities: Understanding the Market Opportunity in the Cities of Tomorrow (Paris: Alcatel-Lucent, 2012) <http://www2.alcatel-lucent.com/knowledge-center/admin/mci-files-1a2c3f/ma/Smart_Cities_Market_opportunity_MarketAnalysis.pdf> Accessed January 1, 2013.

M. Angelidou, "Smart City Policies: A Spatial Approach," Cities: The International Journal of Urban Policy and Planning 41:Supplement 1 (2014) S3-S11.

M. Angelidou, "The Role of Smart City Characteristics in the Plans of Fifteen Cities," Journal of Urban Technology 24:4 (2017) 3-28.

R. Arnkil, A. Järvensivu, P. Koski, \& T. Piirainen, Exploring Quadruple Helix: Outlining User-oriented Innovation Models (Tampere: University of Tampere, 2010) <https://tampub.uta.fi/bitstream/handle/10024/65758/978-951-44-8209-0.pdf?sequence=1> Accessed July 10, 2016.

J. Aschemann-Witzel, I.E. de Hooge, H. Rohm, A. Normann, M. Bonzanini Bossle, A. Grønhøj, \& M. Oostindjer, "Key Characteristics and Success Factors of Supply Chain Initiatives Tackling Consumer-related Food Waste - A Multiple Case Study," Journal of Cleaner Production 155 (2017) 3345.

Aspern Smart City Research, Aspern Smart City Research: Energieforschung Gestaltet Energiezukunft (Vienna: Aspern Smart City Research, 2015) <http://www.ascr.at/wp-content/uploads/2015/09/ASCR_Folder_dt.pdf > Accessed May 3, 2017.

Ayuntament de Barcelona, Compromiso Ciudadano Por La Sostenibilidad 2012-2022 (Barcelona: Ayuntament de Barcelona, 2012) <http://ajuntament.barcelona.cat/ecologiaurbana/sites/default/files/Compromiso\%20Ciudadano\%20por\%20la\%20Sostenibilidad.pdf> Accessed August 5, 2017.

Ayuntament de Barcelona, Smart Cities: Informe Sectorial 2013 (Barcelona: Ayuntament de Barcelona, 
2013) <https://bcnroc.ajuntament.barcelona.cat/jspui/bitstream/11703/86798/1/13754.pdf> Accessed August 5, 2017.

B. Baccarne, D. Schuurman, P. Mechant, \& L. De Marez, "The Role of Urban Living Labs in a Smart City," in XXV ISPIM Innovation Conference: Innovation for Sustainable Economy \& Society (Manchester: International Society for Professional Innovation Management, 2014b).

B. Baccarne, P. Mechant, \& D. Schuurman, "Empowered Cities? An Analysis of the Structure and Generated Value of the Smart City Ghent," in R.P. Dameri \& C. Rosenthal-Sabroux, eds., Smart City: How to Create Public and Economic Value with High Technology in Urban Space (Cham: Springer, 2014a) 157-182.

T. Bakici, E. Almirall, \& J. Wareham, "A Smart City Initiative: The Case of Barcelona," Journal of the Knowledge Economy 4:2 (2013) 135-148.

T. Bednar, D. Bothe, J. Forster, S. Fritz, N. Haufe, T. Kaufmann, P. Eder-Neuhauser, P. Pfaffenbichler, N. Rab, J. Schleicher, G. Weinwurm, C. Winkler, \& M. Ziegler, URBEN-DK: Results Report (Vienna: TU Wien, 2016) <https://urbem.tuwien.ac.at/fileadmin/t/urbem/files/URBEM_Ergebnisbericht_Einzelseiten_EN.pdf> Accessed August 5, 2017.

B. Bergvall-Kåreborn, C. Ihlström Eriksson, A. Ståhlbröst, \& J. Svensson, "A Milieu for Innovation Defining Living Labs," in Proceedings of the 2nd ISPIM Innovation Symposium (Manchester: International Society for Professional Innovation Management (ISPIM), 2009)

R. Bolici \& L. Mora, "Urban Regeneration in the Digital Era: How to Develop Smart City Strategies in Large European Cities," TECHNE: Journal of Technology for Architecture and Environment 5:2 (2015) 110-119.

N. Brandt, F. Cambell, M. Deakin, S. Johansson, M. Malmström, K. Mulder, U. Pesch, H. Shahrokni, O. Tatarchenko, \& L. Årman, European Cities Moving Towards Climate Neutrality (2014) $<$ <ttp://www.clue-project.eu/getfile.ashx?cid=69201\&cc=5\&refid=6> Accessed July 8, 2017.

B. Brech, R. Rajan, J. Fletcher, C. Harrison, M. Hayes, J. Hogan, L. Hopkins, P.K. Isom, J. Meegan, C. Penny, J.L. Snowdon, \& D.A. Wood, Smarter Cities Series: Understanding the IBM Approach to Efficient Buildings (Armonk, NY: IBM Corporation, 2011) <http://www.redbooks.ibm.com/redpapers/pdfs/redp4735.pdf> Accessed September 14, 2012.

J. Breuer, N. Walravens, \& P. Ballon, "Beyond Defining the Smart City: Meeting Top-down and Bottomup Approaches in the Middle," TeMA: Journal of Land Use, Mobility and Environment 7 (2014) 153164.

S. Brunia, I. De Been, \& T.J. van der Voordt, "Accommodating New Ways of Working: Lessons from Best Practices and Worst Cases," Journal of Corporate Real Estate 18:1 (2016) 30-47.

I. Calzada, "The Techno-Politics of Data and Smart Devolution in City-Regions: Comparing Glasgow, Bristol, Barcelona, and Bilbao," Systems 5:1 (2017).

A. Caragliu, C. Del Bo, \& P. Nijkamp, "Smart Cities in Europe," Journal of Urban Technology 18:2 (2011) 65-82.

P. Cardullo \& R. Kitchin, Being a Citizen in the Smart City: Up and Down the Scaffold of Smart Citizen Participation (Maynooth: Maynooth University, 2017) <https://osf.io/preprints/socarxiv/v24jn> Accessed September 12, 2017.

L. Carvalho, "Smart Cities from Scratch? A Socio-technical Perspective," Cambridge Journal of Regions, Economy and Society 8:1 (2015) 43-60.

S. Cavallini, R. Soldi, J. Friedl, \& M. Volpe, Using the Quadruple Helix Approach to Accelerate the Transfer of Research and Innovation Results to Regional Growth (European Union - Committee of the Regions, 2016) <http://cor.europa.eu/en/documentation/studies/Documents/quadruple-helix.pdf> Accessed November 8, 2016.

C. Chen-Ritzo, C. Harrison, J. Paraszczak, \& F. Parr, "Instrumenting the Planet," IBM Journal of Research \& Development 53:3 (2009) 338-353.

E. Christopoulou, D. Ringas, \& J. Garofalakis, "The Vision of the Sociable Smart City," in N. Streitz \& P. Markopoulos, eds., Distributed, Ambient, and Pervasive Interactions: Second International Conference, DAPI 2014, Held as Part of HCl International 2014, Heraklion, Crete, Greece, June 22-27, 2014. Proceedings (Berlin: Springer, 2014) 545-554.

Cisco Systems, Cisco Smart+Connected Digital Platform: At-a-glance (San Jose, CA: Cisco Systems, 2016a) $<$ http://www.cisco.com/c/dam/en_us/solutions/industries/docs/at-a-glance-c45- 
736521.pdf> Accessed June 20, 2017.

Cisco Systems, Cisco Smart+Connected Digital Platform: Data Sheet (San Jose, CA: Cisco Systems, 2016b) <http://www.cisco.com/c/dam/en_us/solutions/industries/docs/datasheet-c78-737127.pdf> Accessed June 20, 2017.

Cisco Systems, Smart Cities Exposé: 10 Cities in Transition (San Jose, CA: Cisco Systems, 2012) $<$ http://www.pageturnpro.com/Cisco/41742-Smart-Cities-Expose-10-Cities-in-Transition/index.html\#44> Accessed January 5, 2013.

City of Vienna, 3420 Aspern Development AG, Siemens AG Österreich, Österreichisches Forschungsund Prüfzentrum Arsenal GesmbH, raum \& kommunikation $\mathrm{GmbH}$, Vienna University of Technology, Energieinstitut der Wirtschaft $\mathrm{GmbH}$, \& Austrian Institute of Technology $\mathrm{GmbH}$, Smart City Wien: Short Report (Vienna: Climate and Energy Fund, 2011) <http://www.smartcities.at/assets/Projektberichte/Endbericht-Kurzfassung/Endbericht-K11NE2F00030-Wien-kurz-dt-englv1.0.pdf> Accessed September 1, 2016.

City of Vienna, 3420 Aspern Development AG, Siemens AG Österreich, Österreichisches Forschungsund Prüfzentrum Arsenal GesmbH, raum \& kommunikation $\mathrm{GmbH}$, Vienna University of Technology, Energieinstitut der Wirtschaft $\mathrm{GmbH}$, \& Austrian Institute of Technology GmbH, Smart City Wien: Vision 2050, Roadmap for 2020 and Beyond, Action Plan for 2012-15 (2013) <https://www.wien.gv.at/stadtentwicklung/studien/pdf/b008218.pdf> Accessed September 1, 2016.

City of Vienna, Smart City Wien Stakeholder Forum: Auf Dem Weg Zur Smart City Wien Rahmenstrategie (Vienna: City of Vienna, 2013a) <https://www.wien.gv.at/stadtentwicklung/studien/pdf/b008381.pdf> Accessed September 1, 2016.

City of Vienna, Smart City Wien Stakeholder Forum: Innovation Durch Smarte Projekte (Vienna: City of Vienna, 2013b) <https://www.wien.gv.at/stadtentwicklung/studien/pdf/b008328.pdf> Accessed September 1, 2016.

City of Vienna, Smart City Wien Stakeholder Forum: Wo Stehen Wir (Vienna: City of Vienna, 2012) <https://www.wien.gv.at/stadtentwicklung/studien/pdf/b008327.pdf> Accessed September 1, 2016.

City of Vienna, Smart City Wien: Framework Strategy (Vienna: City of Vienna, 2014) <https://smartcity.wien.gv.at/site/files/2014/09/SmartCityWien_FrameworkStrategy_english_doublepage.pdf> Accessed August 30, 2016.

City of Vienna, Stakeholder-Prozesse - Smart City Wien (Vienna: City of Vienna, 2016) $<$ https://www.wien.gv.at/stadtentwicklung/projekte/smartcity/stakeholder.html> Accessed September 1, 2016.

Climate and Energy Fund, Smart City Wien (Vienna: Climate and Energy Fund, 2013) <http://www.smartcities.at/city-projects/smart-cities-en-us/smart-city-wien-en-us/> Accessed September 1, 2016.

CLUE Project Partners, Practices, Tools and Policies: European Cities Moving Towards Climate Neutrality (2014) <http://www.clue-project.eu/getfile.ashx?cid=503736\&cc=3\&refid=18> Accessed March 10, 2016.

A. Cocchia, "Smart and Digital City: A Systematic Literature Review," in R.P. Dameri \& C. RosenthalSabroux, eds., Smart City: How to Create Public and Economic Value with High Technology in Urban Space (Berlin: Springer, 2014) 13-43.

C. Coletta, L. Heaphy, \& R. Kitchin, From the Accidental to Articulated Smart City: The Creation and Work of Smart Dublin (Maynooth: Maynooth University, 2017) <https://osf.io/preprints/socarxiv/93ga5> Accessed September 12, 2017.

G. Concilio \& F. Rizzo, eds., Human Smart Cities: Rethinking the Interplay Between Design and Planning (Berlin: Springer, 2016).

M. Cosgrove, W. Harthoorn, J. Hogan, R. Jabbar, M. Kehoe, J. Meegan, \& P. Nesbitt, Smarter Cities Series: Introducing the IBM City Operations and Management Solution (Armonk, NY: IBM Corporation, 2011) <http://www.redbooks.ibm.com/redpapers/pdfs/redp4734.pdf> Accessed September 14, 2012.

R. Cowley, S. Joss, \& Y. Dayot, "The Smart City and Its Publics: Insights from Across Six UK Cities," Urban Research \& Practice (2017) doi: http://dx.doi.org/10.1080/17535069.2017.1293150.

J.W. Creswell, Research Design: Qualitative, Quantitative, and Mixed Methods Approaches (Thousand Oaks, CA: SAGE Publications, 2009). 
F. Cugurullo, "How to Build a Sandcastle: An Analysis of the Genesis and Development of Masdar City," Journal of Urban Technology 20:1 (2013) 23-37.

R.P. Dameri, "Comparing Smart and Digital City: Initiatives and Strategies in Amsterdam and Genoa. Are They Digital and/or Smart?," in R.P. Dameri \& C. Rosenthal-Sabroux, eds., Smart City: How to Create Public and Economic Value with High Technology in Urban Space (Berlin: Springer, 2014) 45-88.

R.P. Dameri, "Searching for Smart City Definition: A Comprehensive Proposal," International Journal of Computers \& Technology 11:5 (2013) 2544-2551.

R.P. Dameri, Smart City Implementation: Creating Economic and Public Value in Innovative Urban Systems (Cham: Spring, 2017).

A. Datta, "New Urban Utopias of Postcolonial India: Entrepreneurial Urbanization in Dholera Smart City, Gujarat," Dialogues in Human Geography 5:1 (2015) 3-22.

M. Deakin \& H. Al Wear, "From Intelligent to Smart Cities," Intelligent Buildings International 3:3 (2011) 140-152.

M. Deakin \& L. Leydesdorff, "The Triple Helix Model of Smart Cities: A Neo-Evolutionary Perspective," in M. Deakin, ed., Smart Cities: Governing, Modelling and Analyzing the Transition (New York, NY: Routledge, 2014) 134-149.

M. Deakin, ed., Smart Cities: Governing, Modelling and Analysing the Transition (New York City, NY: Routledge, 2014).

Digital City Wien, Digital City Wien Aktionstag Am 14. September @ Wiener Forschungsfest (2015) <https://digitalcity.wien/digital-city-wien-wiener-forschungsfest-2015/> Accessed August 24, 2017.

Digital City Wien, Digitaler Salon (2016) <https://digitalcity.wien/digitaler-salon/> Accessed August 24, 2017.

L. Dijkstra \& H. Poelman, Cities in Europe: The New OECD-EC Definition (Brussels: European Commission, 2012) <http://ec.europa.eu/regional_policy/sources/docgener/focus/2012_01_city.pdf> Accessed March 5, 2017.

S. Dirks \& M. Keeling, A Vision of Smarter Cities: How Cities Can Lead the Way Into a Prosperous and Sustainable Future (Somers, NY: IBM Corporation, 2009) <http://www-03.ibm.com/press/attachments/IBV_Smarter_Cities_-_Final.pdf> Accessed February 3, 2012.

S. Dirks, C. Gurdgiev, \& M. Keeling, Smarter Cities for Smarter Growth: How Cities Can Optimize Their Systems for the Talent-based Economy (Somers, NY: IBM Corporation, 2010) <http://public.dhe.ibm.com/common/ssi/ecm/en/gbe03348usen/GBE03348USEN.PDF> Accessed February 3, 2012.

S. Dirks, M. Keeling, \& J. Dencik, How Smart Is Your City: Helping Cities Measure Progress (Somers, NY: IBM Corporation, 2009) <http://public.dhe.ibm.com/common/ssi/ecm/en/gbe03248usen/GBE03248USEN.PDF> Accessed June 6, 2014.

K.M. Eisenhardt \& M.E. Graebner, "Theory Building from Cases: Opportunities and Challenges," Academy of Management Journal 50:1 (2007) 25-32.

K.M. Eisenhardt, "Building Theories from Case Study Research," Academy of Management Review 14:4 (1989) 532-550.

A. Ersoy, "Smart Cities as a Mechanism Towards a Broader Understanding of Infrastructure Interdependencies," Regional Studies, Regional Science 4:1 (2017) 1-6.

H. Etzkowitz \& L. Leydesdorff, "The Dynamics of Innovation: From National Systems and "Mode 2" to a Triple Helix of University-industry-government Relations," Research Policy 29:2 (2000) 109-123.

European Commission, Barcelona Is "iCapital" of Europe (Brussels: European Commission, 2014a) <http://europa.eu/rapid/press-release_IP-14-239_en.htm?locale=en> Accessed March 13, 2014.

European Commission, Call FP7-ENERGY-SMARTCITIES-2012 (European Commission, 2011) $<$ https://ec.europa.eu/research/participants/portal/doc/call/fp7/fp7-energy-smartcities-2012/31559fiche_fp7-energy-2012-smartcities_en.pdf> Accessed February 10, 2016.

European Commission, Call FP7-SMARTCITIES-2013 (European Commission, 2012a) <https://ec.europa.eu/research/participants/portal/doc/call/fp7/fp7-smartcities-2013/32801-call_fiche_fp7smartcities-2013_en.pdf> Accessed February 10, 2016.

European Commission, Communication from the Commission to the European Parliament, the Council, 
the European Economic and Social Committee and the Committee of the Regions. Investing in the Development of Low Carbon Technologies (SET-Plan) (Brussels: European Commission, 2009) <http://eur-lex.europa.eu/legal-content/IT/TXT/PDF/?uri=CELEX:52009DC0519\&from=EN> Accessed February 2, 2014.

European Commission, Communication from the Commission: Smart Cities and Communities - European Innovation Partnership (Brussels: European Commission, 2012b) <http://eur-lex.europa.eu/legal-content/IT/TXT/PDF/?uri=CELEX:52009DC0519\&from=EN> Accessed February 2, 2014.

European Commission, Horizon 2020 Work Programme 2016-2017: Cross-cutting Activities (Focus Areas) (European Commission, 2016) <http://ec.europa.eu/research/participants/data/ref/h2020/wp/2016_2017/main/h2020-wp1617-focus_en.pdf> Accessed January 20, 2017.

European Commission, Promoting Civil Society Participation in Policy and Budget Processes (Luxembourg: Publications Office of the European Union, 2014) <https://europa.eu/capacity4dev/file/26280/download?token=hKjUXKEa> Accessed April 26, 2017.

European Innovation Partnership on Smart Cities and Communities, European Innovation Partnership on Smart Cities and Communities Strategic Implementation Plan (European Commission, 2013) <http://ec.europa.eu/eip/smartcities/files/sip_final_en.pdf> Accessed March 28, 2017.

J. Exner, "Smart Cities - Field of Application for Planning Support Systems in the 21st Century?," in Proceedings Computers in Urban Planning and Urban Management 2015 (Cambridge, MA: Massachusetts Institute of Technology, 2015).

J. Ferrer, "Barcelona's Smart City Vision: An Opportunity for Transformation," Field Actions Science Reports Special Issue:16 (2017) 70-75.

K.J. Fietkiewicz \& W.G. Stock, "How Smart Are Japanese Cities? An Empirical Investigation of Infrastructures and Governmental Programs in Tokyo, Yokohama, Osaka and Kyoto," in T.X. Bui \& R.H. Sprague, eds., Proceedings of the 48th Hawaii International Conference on System Sciences (HICSS) (Piscataway, NJ: Institute of Electrical and Electronics Engineers, 2015) 2345-2354.

Food and Agriculture Organization, FAO Strategy for Partnerships with Civil Society Organizations (Rome: Food and Agriculture Organization, 2013) <http://www.fao.org/3/a-i3443e.pdf> Accessed May 27, 2017.

N. Gardner \& L. Hespanhol, "SMLXL: Scaling the Smart City, From Metropolis to Individual," City, Culture and Society 12 (2018) 54-61.

A.L. George \& A. Bennett, Case Studies and Theory Development in the Social Sciences (Cambridge, MA: MIT Press, 2005).

J. Gerring, "What Is a Case Study and What Is It Good For?," American Political Science Review 98:2 (2004) 341-354.

M. Gibbert, W. Ruigrok, \& B. Wicki, "What Passes As a Rigorous Case Study?," Strategic Management Journal 29:13 1465-1474.

G.R. Gibbs, Analysing Qualitative Data (Thousand Oaks, California, United States: SAGE Publications, 2007).

R. Giffinger, C. Ferter, H. Kramar, R. Kalasek, N. Pichler-Milanović, \& E. Meijers, Smart Cities: Ranking of European Medium-sized Cities (Vienna: Vienna University of Technology - Centre of Regional Science (SRF), 2007) <http://www.smart-cities.eu/download/smart_cities_final_report.pdf>Accessed May 9, 2012.

D. Gooch, A. Wolff, G. Kortuem, \& R. Brown, "Reimagining the Role of Citizens in Smart City Projects," in UbiComp/ISWC'15 Adjunct: Adjunct Proceedings of the 2015 ACM International Joint Conference on Pervasive and Ubiquitous Computing and Proceedings of the 2015 ACM International Symposium on Wearable Computers (New York, NY: ACM, 2015) 1587-1594.

G. Grossi \& D. Pianezzi, "Smart Cities: Utopia or Neoliberal Ideology?," Cities: The International Journal of Urban Policy and Planning 69 (2017) 79-85.

K. Gupta \& R.P. Hall, "The Indian Perspective of Smart Cities," in Proceedings of the 2017 Smart City Symposium Prague (SCSP) (Piscataway, NJ: Institute of Electrical and Electronics Engineers, 2017).

C. Harrison, B. Eckman, R. Hamilton, P. Hartswick, J. Kalagnanam, J. Paraszczak, \& P. Williams, 
"Foundations for Smarter Cities," IBM Journal of Research and Development 54:4 (2010) 1-16.

C. Harrison, J. Paraszczak, \& R.P. Williams, "Preface: Smarter Cities," IBM Journal of Research and Development 55:1-2 (2011) 1-5.

S. Hartmann, P. Hlava, L. Tiede, M. Kintisch, U. Mollay, C. Schremmer, T. Brajovic, A. Breitfuss, S. Leitner, T. Brus, K. Weninger, \& R. Kalasek, Transformation Agenda Vienna (2015) <http://urbantransform.eu/wp-content/uploads/sites/2/2015/07/D2.2_Transformation-Agenda-Vienna.pdf> Accessed May 12, 2016.

S. Heissenberger \& T. Schuhböck, Partizipationsprozess Digitale Agenda Wien (Vienna: City of Vienna, 2015) <http://www.egovernment-wettbewerb.de/praesentationen/2015/stadt_wien_praesentation.pdf> Accessed August 30, 2016.

H. Hemis, W. Schmid, U. Gigler, G. den Boogert, S. Muller, H. Stock, D. Uuong, S. Emery, E. Meskel, P. Weber, J. Jaeger, L. Ljungqvist, S. Geier, A. Olszak, M. Wróblewski, M. Santman, S. Malnar Neralić, N. Mornar, M. Matasović, \& M. Zidar, Integrating Energy in Urban Planning Processes Insights From Amsterdam/Zaanstad, Berlin, Paris, Stockholm, Vienna, Warsaw and Zagreb (2017) <http://www.urbanlearning.eu/fileadmin/user_upload/documents/D4-2_Synthesis-report_upgraded_processes_final_170807.pdf> Accessed September 5, 2017.

D. Hemment \& A. Townsend, eds., Smart Citizens (Manchester: FutureEverything, 2013).

K. Hofstetter \& A. Vogl, "Smart City Wien: Vienna's Stepping Stone into the European Future of Technology and Climate," in M. Schrenk, V.V. Popovich, \& P. Zeile, eds., REAL CORP 2011. Change for Stability: Lifecycles of Cities and Regions. The Role and Possibilities of Foresighted Planning in Transformation Processes. Proceedings of 16th International Conference on Urban Planning, Regional Development and Information Society (Schwechat: Competence Center of Urban and Regional Planning (CORP), 2011) 1373-1382.

R.G. Hollands, "Beyond the Corporate Smart City? Glimpses of Other Possibilities of Smartness," in S. Marvin, A. Luque-Ayala, \& C. McFarlane, eds., Smart Urbanism: Utopian Vision or False Dawn? (New York City, NY: Routledge, 2016) 168-184.

R.G. Hollands, "Critical Interventions into the Corporate Smart City," Cambridge Journal of Regions, Economy and Society 8:1 (2015) 61-77.

R.G. Hollands, "Will the Real Smart City Please Stand Up?," City: analysis of urban trends, culture, theory, policy, action 12:3 (2008) 303-320.

I amsterdam, Amsterdam Smart City Wins City Star Award (Amsterdam: I amsterdam, 2011) <http://www.iamsterdam.com/city\%20star\%20award> Accessed June 23, 2015.

IBM Corporation, IBM Smarter Cities Challenge (Armonk, NY: IBM Corporation, 2017a) <https://www.smartercitieschallenge.org> Accessed March 20, 2017.

IBM Corporation, IBM Smarter Planet (Armonk, NY: IBM Corporation, 2017b) <http://www03.ibm.com/ibm/history/ibm100/us/en/icons/smarterplanet> Accessed March 20, 2017.

IDC, IDC Smart Cities Österreich 2016 Studie (IDC, 2016) <http://idc-austria.at/de/research/local-studies> Accessed August 10, 2017.

J.S. Katz \& J. Ruano, Smarter Cities Series: Understanding the IBM Approach to Energy Innovation (Armonk, NY: IBM Corporation, 2011) <http://www.redbooks.ibm.com/redpapers/pdfs/redp4739.pdf> Accessed September 14, 2012.

M. Kehoe, M. Cosgrove, S. De Gennaro, C. Harrison, W. Harthoorn, J. Hogan, J. Meegan, P. Nesbitt, \& C. Peters, Smarter Cities Series: A Foundation for Understanding IBM Smarter Cities (Armonk, NY: IBM Corporation, 2011) <http://www.redbooks.ibm.com/redpapers/pdfs/redp4733.pdf> Accessed September 14, 2012.

R. Kitchin, The Data Revolution: Big Data, Open Data, Data Infrastructures and Their Consequences (Thousand Oaks, CA: SAGE Publications, 2014a).

R. Kitchin, "The Real-time City? Big Data and Smart Urbanism," GeoJournal 79:1 (2014b) 1-14.

M. Kohno, Y. Masuyama, N. Kato, \& A. Tobe, "Hitachi's Smart City Solutions for New Era of Urban Development," Hitachi Review 60:2 (2011) 79-88.

N. Komninos \& L. Mora, "Exploring the Big Picture of Smart City Research," Scienze Regionali: Italian Journal of Regional Science (2018) [in press]. 
N. Komninos, "Intelligent Cities: Variable Geometries of Spatial Intelligence," Intelligent building international 3:3 (2011) 172-188.

N. Komninos, The Age of Intelligent Cities: Smart Environments and Innovation-for-all Strategies (New York City, NY: Routledge, 2014).

J. Kotkin, The World's Smartest Cities (Forbes, 2009) <http://www.forbes.com/2009/12/03/infrastructure-economy-urban-opinions-columnists-smart-cities-09-joel-kotkin.html> Accessed September 5, 2016.

K. Kourtit, M. Deakin, A. Caragliu, C. Del Bo, P. Nijkamp, P. Lombardi, \& S. Giordano, "An Advanced Triple Helix Network Framework for Smart Cities Performance," in M. Deakin, ed., Smart Cities: Governing, Modelling and Analyzing the Transition (New York, NY: Routledge, 2014) 196-216.

T. Kurebayashi, Y. Masuyama, K. Morita, N. Taniguchi, \& F. Mizuki, "Global Initiatives for Smart Urban Development," Hitachi Review 60:2 (2011) 89-93.

J. Lee \& M.G. Hancock, Toward a Framework for Smart Cities: A Comparison of Seoul, San Francisco and Amsterdam (Yonsei University and Stanford University, 2012) <http://iis-db.stanford.edu/evnts/7239/Jung_Hoon_Lee_final.pdf> Accessed June 12, 2014.

J. Lee, M.G. Hancock, \& M. Hu, "Towards an Effective Framework for Building Smart Cities: Lessons from Seoul and San Francisco," Technological Forecasting and Social Change 89 (2014) 80-99.

L. Leydesdorff \& M. Deakin, "The Triple-helix Model of Smart Cities: A Neo-evolutionary Perspective," Journal of Urban Technology 18:2 (2011) 53-63.

X. Li, H. Yang, W. Li, \& Z. Chen, "Public-private Partnership in Residential Brownfield Redevelopment: Case Studies of Pittsburg," Procedia Engineering 145 (2016) 1534-1540.

D. Ludlow, Z. Khan, K. Soomro, M. Marconcini, R. San Jose, P. Malcorps, M. Lemper, J. Luis Perez, \& A. Metz, "From Top-down Land Use Planning Intelligence to Bottom-up Stakeholder Engagement for Smart Cities - a Case Study: DECUMANUS Service Products," International Journal of Services Technology and Management (2017).

C. Manville, G. Cochrane, J. Cave, J. Millard, J.K. Pederson, R.K. Thaarup, A. Liebe, M. Wissner, R. Massink, \& B. Kotterink, Mapping Smart City in the EU (Brussels: European Parliament - Directorate-General for Internal Policies, 2014) <http://www.europarl.europa.eu/RegData/etudes/etudes/join/2014/507480/IPOL-ITRE_ET(2014)507480_EN.pdf> Accessed February 5, 2014

H. March, "The Smart City and Other ICT-led Techno-imaginaries: Any Room for Dialogue with Degrowth?," Journal of Cleaner Production (2016) doi: https://doi.org/10.1016/j.jclepro.2016.09.154.

C. Marguerite, N. Pardo Garcia, E. Haslinger, I. Monteverdi, G. Santicelli, \& R. Abdurafikov, CityOpt Holistic Simulation and Optimization of Energy Systems in Smart Cities: Vienna Demonstrator (2016) <http://cityopt.eu/Deliverables/D33.pdf> Accessed February 1, 2017.

D. McNeill, "IBM and the Visual Formation of Smart Cities," in S. Marvin, A. Luque-Ayala, \& C. McFarlane, eds., Smart Urbanism: Utopian Vision or False Dawn? (New York City, NY: Routledge, 2016) 34-51.

M.B. Miles \& M.A. Huberman, Qualitative Data Analysis: An Expanded Sourcebook (Thousand Oaks, CA: SAGE Publications, 1994).

L. Mora \& R. Bolici, "How to Become a Smart City: Learning from Amsterdam," in A. Bisello, D. Vettorato, R. Stephens, \& P. Elisei, eds., Smart and Sustainable Planning for Cities and Regions: Results of SSPCR 2015 (Cham: Springer, 2017) 251-266.

L. Mora \& R. Bolici, "The Development Process of Smart City Strategies: The Case of Barcelona," in J. Rajaniemi, ed., Re-city: Future City - Combining Disciplines (Tampere: Juvenes print, 2016) 155181.

L. Mora, M. Deakin, \& A. Reid, "Smart City Development Paths: Insights from the First Two Decades of Research," in A. Bisello, D. Vettorato, P. Laconte, \& S. Costa, eds., Smart and Sustainable Planning for Cities and Region: Results of SSPCR 2017 (Cham: Springer, 2018) 403-427.

L. Mora, R. Bolici, \& M. Deakin, "The First Two Decades of Smart-City Research: A Bibliometric Analysis," Journal of Urban Tecnology 24:1 (2017) 3-27.

P. Muhlmann, Smart City Wien: The City for Life (Vienna: TINA Vienna GmbH, 2017) <https://www.pub- 
licconsulting.at/fileadmin/user_upload/media/kpc-consulting/Austrian_CC_Workshop_2017/2._P._Muehlmann_Tina_Vienna_Austrian_CC_WS_2017.pdf $\overline{7}$ Accessed August 5, 2017.

P. Neirotti, A. De Marco, A.C. Cagliano, G. Mangano, \& F. Scorrano, "Current Trends in Smart City Initiatives: Some Stylised Facts," Cities: The International Journal of Urban Policy and Planning 38 (2014) 25-36.

V. Niaros, "Introducing a Taxonomy of the "Smart City": Towards a Commons-Oriented Approach?," tripleC 14:1 (2016) 51-61.

M. Ornetzeder \& H. Rohracher, "Of Solar Collectors, Wind Power, and Car Sharing: Comparing and Understanding Successful Cases of Grassroots Innovations," Global Environmental Change 23:5 (2013) 856-867.

M.Q. Patton, Qualitative Research and Evaluation Methods (Thousand Oaks, CA: SAGE Publications, 2002).

S. Paroutis, M. Bennett, \& L. Heracleous, "A Strategic View on Smart City Technology: The Case of IBM Smarter Cities During a Recession," Technological Forecasting and Social Change 89 (2014) 262-272.

A. Paul, M. Cleverley, W. Kerr, F. Marzolini, M. Reade, \& S. Russo, Smarter Cities Series: Understanding the IBM Approach to Public Safety (Armonk, NY: IBM Corporation, 2011) <http://www.redbooks.ibm.com/redpapers/pdfs/redp4738.pdf> Accessed September 14, 2012.

A. Pollio, "Technologies of Austerity Urbanism: The "smart City" Agenda in Italy (2011-2013)," Urban Geography 37:4 (2016) 514-534.

C. Ratti \& A. Townsend, "The Social Nexus," Scientific American (September 2011) 42-48.

R.K. Reddy Kummitha \& N. Crutzen, "How Do We Understand Smart Cities? An Evolutionary Perspective," Cities: The International Journal of Urban Policy and Planning 67 (2017) 43-52.

E. Reviglio, S. Camerano, A. Carriero, G. Del Bufalo, D. Alterio, M. Calderini, A. De Marco, F.V. Michelucci, P. Neirotti, \& F. Scorrano, Smart City: Development Projects and Financial Instruments (Rome: Cassa depositi e prestiti, 2013) <http://www.cassaddpp.it/static/upload/mon/monographicreport_smart-city.pdf> Accessed February 26, 2014.

C. Robson, Real World Research: A Resource for Users of Social Research Methods in Applied Settings (Hoboken, NJ: John Wiley \& Sons Ltd, 1993). J. Ruano, T. Chao, P. Hartswick, B. Havers, J. Meegan, S. Wasserkrug, \& P. Williams, Smarter Cities Series: Understanding the IBM Approach to Water Management (Armonk, NY: IBM Corporation, 2011) <http://www.redbooks.ibm.com/redpapers/pdfs/redp4736. pdf> Accessed September 14, 2012.

S. Sauer, "Do Smart Cities Produce Smart Entrepreneurs?," Journal of Theoretical and Applied Electronic Commerce Research 7:3 (2012) 63-73.

S. Schaefer, C. Harrison, N. Lamba, \& V. Srikanth, Smarter Cities Series: Understanding the IBM Approach to Traffic Management (Armonk, NY: IBM Corporation, 2011) <http://www.redbooks.ibm.com/redpapers/pdfs/redp4737.pdf> Accessed September 14, 2012.

H. Schaffers, N. Komninos, M. Pallot, M. Aguas, E. Almirall, T. Bakici, J. Barroca, D. Carter, M. Corriou, J. Fernadez, H. Hielkema, A. Kivilehto, M. Nilsson, A. Oliveira, E. Posio, A. Sällström, R. Santoro, B. Senach, I. Torres, P. Tsarchopoulos, B. Trousse, P. Turkama, \& J. Lopez Ventura, Smart Cities As Innovation Ecosystems Sustained by the Future Internet (2012) <http://hal.archives-ouvertes.fr/docs/00/76/96/35/PDF/FIREBALL-White-Paper-Final2.pdf> Accessed August 24, 2011.

D. Schuurman, B. Baccarne, L. De Marez, \& P. Mechant, "Smart Ideas for Smart Cities: Investigating Crowdsourcing for Generating and Selecting Ideas for ICT Innovation in a City Context," Journal of Theoretical and Applied Electronic Commerce Research 7:3 (2012) 49-62.

D. Schuurman, L. De Marez, \& P. Ballon, "The Impact of Living Lab Methodology on Open Innovation Contributions and Outcomes," Technology Innovation Management Review 6:1 (2016) 7-16.

J. Seawright \& J. Gerring, "Case Selection Techniques in Case Study Research: A Menu of Qualitative and Quantitative Options," Political Research Quarterly 61:2 (2008) 294-308.

C. Selada, "Smart Cities and the Quadruple Helix Innovation Systems Conceptual Framework: The Case of Portugal," in S. Monteiro \& E.G. Carayannis, eds., The Quadruple Innovation Helix Nexus: A Smart Growth Model, Quantitative Empirical Validation and Operationalization for OECD Countries (New York City, NY: Palgrave, 2017) 211-244. 
M. Shakir, "The Selection of Case Studies: Strategies and Their Applications to IS Implementation Cases Studies," Research Letters in the Information and Mathematical Sciences 3 (2002) 191-198.

D. Shin, "A Critique of Korean National Information Strategy: Case of National Information Infrastructures," Government Information Quarterly 24:3 (2007) 624-645.

D. Shin, "Ubiquitous City: Urban Technologies, Urban Infrastructure and Urban Informatics," Journal of Information Science 35:5 (2009) 515-526.

D. Shin \& T. Kim, "Large-scale ICT Innovation and Policy," in D.F. Kocaoglu, T.R. Anderson, T.U. Daim, A. Jetter, \& C.M. Weber, eds., PICMET 2010 Proceedings: Technology Management for Global Economic Growth (Piscataway, NJ: Institute of Electrical and Electronics Engineers (IEEE), 2010) 148-161.

S.T. Shwayri, "A Model Korean Ubiquitous Eco-city? The Politics of Making Songdo," Journal of Urban Technology 20:1 (2013) 39-55.

Siemens AG, Our Future Depends on Intelligent Infrastructures (Munich: Siemens AG, 2014) $<$ https://www.siemens.com/digitalization/public/pdf/siemens-intelligent-infrastructure.pdf $>\quad$ Accessed March 6, 2017.

O. Soderstrom, T. Paasche, \& F. Klauser, "Smart Cities as Corporate Storytelling," City: analysis of urban trends, culture, theory, policy, action 18:3 (2014) 307-320.

R.E. Stake, "Case Studies," in N.K. Denzin \& Y.S. Lincoln, eds., Strategies of Qualitative Inquiry (Thousand Oaks, CA: SAGE Publications, 1998) 86-109.

R.E. Stake, "The Case Study Method in Social Inquiry," Educational Researcher 7:2 (1978) 5-8.

R.E. Stake, The Art of Case Study Research (Thousand Oaks, CA: SAGE Publications, 1995).

A. Strauss \& J.M. Corbin, Basics of Qualitative Research: Grounded Theory Procedures and Techniques (Thousand Oaks, CA: SAGE Publications, 1990).

J. Sujata, S. Saksham, T. Godbole, \& Shreya, "Developing Smart Cities: An Integrated Framework," Procedia Computer Science 93 (2016) 902-909.

H. Tamai, "Fujitsu's Approach to Smart Cities," FUJITSU Scientific \& Technical Journal 50:2 (2014) 310.

A. Townsend, Smart Cities: Big Data, Civic Hackers, and the Quest for a New Utopia (New York City, NY: W.W. Norton \& Company Ltd, 2013).

United Nations, Arrangements and Practices for the Interaction of Non-Governmental Organizations in All Activities of the United Nations System (New York City, NY: United Nations - Department of Economic and Social Affairs, 1998) <http://www.un.org/documents/ga/docs/53/plenary/a53170.htm> Accessed May 15, 2017.

A. Vanolo, "Smartmentality: The Smart City as Disciplinary Strategy," Urban Studies 51:5 (2014) 883898.

P. van Waart, I. Mulder, \& C. de Bont, "A Participatory Approach for Envisioning a Smart City," Social Science Computer Review 34:6 (2016) 708-723.

W. van Winden \& D. van den Buuse, "Smart City Pilot Projects: Exploring the Dimensions and Conditions of Scaling Up," Journal of Urban Technology 24:4 (2017) 51-72.

D. Velthausz, Amsterdam Smart City (Amsterdam: Amsterdam Smart City, 2011) <http://www.slideshare.net/lisa/amsterdam-smart-city-eng-presentation-2-32011-7131457> Accessed August 2, 2016.

J. Viitanen \& R. Kingston, "Smart Cities and Green Growth: Outsourcing Democratic and Environmental Resilience to the Global Technology Sector," Environment and Planning A 46:4 (2014) 803-819.

N. Walravens, "Mobile City Applications for Brussels Citizens: Smart City Trends, Challenges and a Reality Check," Telematics and Informatics 32:2 (2015) 282-299.

Wien Holding $\mathrm{GmbH}$, Quality of Life for Vienna (Vienna: Wien Holding GmbH, 2012) $<$ https://www.wienholding.at/tools/uploads/folderbroschueren/WienHolding-English.pdf > Accessed October 20, 206.

Wiener Modellregion \& Climate and Energy Fund, Statusbericht Der Wiener Modellregion "e-mobility on Demand" (Wiener Modellregion and Climate and Energy Fund, 2014) <https://www.klimafonds.gv.at/assets/Uploads/Themenprojekte/Modellregionen/e-mobility-on-demand-Wien/201504-Statusberichtemobility-on-demand-Wienfinal.pdf> Accessed October 9, 2015. 
E. Woods, D. Alexander, R. Rodriguez Labastida, \& R. Watson, UK Smart Cities Index: Assessment of Strategy and Execution for 10 Cities (Boulder, CO: Navigant Consulting, 2016) <https://www.navigantresearch.com/wp-assets/brochures/Huawei-Navigant-Research-UK-Smart-Cities-IndexWhite-Paper-5-18-2016.pdf> Accessed August 31, 2017.

World Economic Forum, The Future Role of Civil Society (Geneva: World Economic Forum, 2013) <http://www3.weforum.org/docs/WEF_FutureRoleCivilSociety_Report_2013.pdf> Accessed May 1, 2017.

T. Yigitcanlar \& M. Kamruzzaman, "Does Smart City Policy Lead to Sustainability of Cities?," Land Use Policy 73 (2018) 49-58.

T. Yigitcanlar \& S.H. Lee, "Korean Ubiquitous-eco-city: A Smart-sustainable Urban Form or a Branding Hoax?," Technological Forecasting \& Social Change 89 (2014) 100-114.

R.K. Yin, Applications of Case Study Research (Thousand Oaks, CA: SAGE Publications, 2012).

R.K. Yin, Case Study Research: Design and Methods (Thousand Oaks, CA: SAGE Publications, 2009).

Y. Yoshikawa, K. Tada, S. Furuya, \& K. Koda, "Actions for Realizing Next-generation Smart Cities," Hitachi Review 60:6 (2011) 89-93.

T. Zelt, J. Ibel, \& F. Tuncer, THINK ACT: Smart City, Smart Strategy (Munich: Roland Berger GmbH, 2017) <https://www.rolandberger.com/publications/publication_pdf/ta_17_008_smart_cities_online.pdf> Accessed August 31, 2017.

S. Zygiaris, "Smart City Reference Model: Assisting Planners to Conceptualize the Building of Smart City Innovation Ecosystems," Journal of the Knowledge Economy 4:2 (2013) 217-231. 